\title{
Home-based exercise program in TSP/HAM individuals: a feasibility and effectiveness study
}

\author{
Programa de exercícios domiciliares em indivíduos com PET/MAH: um estudo de \\ viabilidade e efetividade
}

\author{
Livia D Facchinetti1, Abelardo Q Araújo², Marcus TT Silva², Ana Claudia C Leite², Mariana FAzevedo', Gisele \\ L Chequer ${ }^{1}$, Raquel VC Oliveira ${ }^{3}$, Arthur S Ferreira ${ }^{4,5}$, Marco Antonio Lima $^{2}$
}

\begin{abstract}
Objective: To investigate the feasibility and effectiveness of a home-based exercise program in TSP/HAM individuals. Methods: Twenty-three TSP/HAM individuals divided in two groups according to Timed Up and Go (TUG) score ( 20 s vs $\geq 20$ s) performed a 20-week home-based exercise program. The primary outcomes were exercise adherence, maximum voluntary isometric contraction of lower limbs (MVIC), Barthel Index and SF-36. Secondary outcomes were adverse effects and barriers to exercise practice. Results: MVIC and the social functioning domain in SF-36 improved significantly in TUG <20s group. The individuals in the TUG $\geq 20$ s group improved significantly their physical functioning domain in SF-36. The total adherence to the 20-week home-based exercise program was $90 \%$. There were mild to moderate adverse events related to exercise program. There were no adverse events related to MVIC test. Conclusions: The home-based exercise program was feasible and effective in improving disability and quality of life in individuals with TSP/HAM.
\end{abstract}

Keywords: paraparesis, tropical spastic; physical therapy speciality; exercise; muscle strength; quality of life.

\section{RESUMO}

Objetivo: Investigar a viabilidade e eficácia de um programa de exercícios domiciliares (PED) em indivíduos com PET/MAH. Métodos: 23 indivíduos com PET/MAH divididos em dois grupos conforme teste Timed Up and Go - TUG ( 220 s vs $\geq 20$ s) realizaram o PED durante 20 semanas. Desfechos primários - adesão aos exercícios, contração isométrica voluntária máxima dos membros inferiores (CIVM), Índice de Barthel e SF-36. Desfechos secundários - ocorrência de eventos adversos e presença de barreiras à prática de exercícios. Resultados: CIVM e componente "Aspectos Sociais" da SF-36 aumentaram significativamente no grupo TUG <20s. Os indivíduos do grupo TUG $\geq 20$ s aumentaram significativamente componente "Capacidade Funcional" da SF-36. A adesão ao PED foi de 90\%. Foram observados eventos adversos de intensidade leve a moderada relacionados ao PED. Não foram encontrados eventos adversos relacionados à CIVM. Conclusões: O PED é viável e eficaz em melhorar a incapacidade e a qualidade de vida de indivíduos com PET/MAH.

Palavras-chave: paraparesia espástica tropical; fisioterapia; exercício; força muscular; qualidade de vida.

Tropical spastic paraparesis/human T-cell lymphotropic virus (HTLV-1)- associated myelopathy (TSP/HAM) is a neurological disease characterized by a progressive paraparesis with pyramidal signs associated with mild sensory signs and sphincter disturbances ${ }^{1,2}$. The neurological impairments lead to difficulties in locomotion and bladder management ${ }^{3}$, frequent falls ${ }^{4}$ as well as poor quality of life $\mathrm{f}^{5,6}$.
Physical therapy has been mentioned as a possible symptomatic non-pharmacologic treatment aimed to prevent contractures and atrophy, improve strength and mobility and attenuate pain and a neurogenic bladder ${ }^{3,7,8,9}$. However, to our knowledge, there is a lack of studies that have investigated the effects of physiotherapeutic interventions/exercises in TSP/HAM individuals.

${ }^{1}$ Fundação Oswaldo Cruz, Instituto Nacional de Infectologia Evandro Chagas, Serviço de Fisioterapia, Rio de Janeiro RJ, Brasil;

${ }^{2}$ Fundação Oswaldo Cruz, Instituto Nacional de Infectologia Evandro Chagas, Laboratório de Pesquisa Clínica em Neuroinfecção, Rio de Janeiro RJ, Brasil; ${ }^{3}$ Fundação Oswaldo Cruz, Instituto Nacional de Infectologia Evandro Chagas, Laboratório de Epidemiologia Clínica, Rio de Janeiro RJ, Brasil;

${ }^{4}$ Centro Universitário Augusto Motta, Programa de Pós-Graduação em Ciências da Reabilitação, Laboratório de Simulação Computacional e Modelagem em Reabilitação, Rio de Janeiro RJ, Brasil;

5Universidade Salgado de Oliveira, Programa de Graduação em Fisioterapia, Rio de Janeiro RJ, Brasil.

Correspondence: Lívia D. Facchinetti; Serviço de Fisioterapia, Instituto Nacional de Infectologia Evandro Chagas (INI) / Fundação Oswaldo Cruz (FIOCRUZ); Av Brasil, 4365; 21040-360 Rio de Janeiro RJ, Brasil; E-mail: livia.dumont@ini.fiocruz.br

Conflict of interest: There is no conflict of interest to declare.

Received 15 April 2016; Received in final form 04 July 2016; Accepted 22 December 2016. 
In clinical practice, TSP/HAM patients frequently report difficulties in attending rehabilitation clinics, mostly because of problems with transportation, poor mobility and the lack of a caregiver/family member to accompany them to the sessions. In a previous study by our group, we identified that approximately $40 \%$ of the TSP/HAM patients did not practice any kind of regular physical activity, including physical therapy ${ }^{4}$. Notably, the majority of TSP/HAM patients are from limited-resource regions, such as Latin America and the Caribbean Islands, where the access to public services is difficult.

Barriers to practicing exercises in site-based programs have also been reported in other populations ${ }^{10,11}$. Home-based exercises could be an alternative strategy to increase the long-term adherence to rehabilitation ${ }^{12,13}$.

Considering the chronic evolution of TSP/HAM and the above-cited barriers, we hypothesized that a home-based exercise program could be a feasible and effective method to offer physiotherapeutic assistance to TSP/HAM patients. The aims of the study were (1) to investigate the feasibility and effectiveness of a 20-week home-based exercises program in TSP/HAM individuals and (2) to verify the presence of adverse events and barriers associated with the home-based exercises program.

\section{METHODS}

\section{Study design}

This was a case series study in which we investigated the effects of a 20-week home-based exercise program in individuals with TSP/HAM. The Instituto Nacional de Infectologia Evandro Chagas (INI/FIOCRUZ) Ethical Committee approved the study and all the participants signed the informed consent.

\section{Participants}

Participants were recruited at the Neurology outpatient clinic at INI/FIOCRUZ. The inclusion criteria were: age $\geq 18$ years old; definite or probable TSP/HAM diagno$\operatorname{sis}^{14}$; being able to walk at least $20 \mathrm{~m}$ with or without an assistive device and to not have practiced any kind of exercise for at least the last month. For the purpose of this work, the term "exercise" was defined as: a type of physical activity that is planned, structured, repetitive and is purposely aimed at improving physical fitness ${ }^{15}$. The exclusion criteria were co-infection with HIV, diagnosis of other neurological diseases, a concomitant medical problem that could interfere with the ability of the patient to participate in the study, and cognitive impairment.

\section{Interventions}

The home-based exercises program aimed to minimize the impairments and the activity limitations in TSP/HAM individuals ${ }^{3,4,8}$. It consisted of stretching and resistive exercises that could: 1) be done without the assistance of anyone; 2) be facilitated through changes in posture of the individual in favor of gravity and 3) could be hampered through the use of elastic bands. The instructions of the exercises were written and illustrated in a chart to facilitate comprehension.

The individuals were asked to perform all the exercises twice a week, which comprised 10 lower limb and abdominal exercises (five stretching and five resistive exercises). The static stretching exercises targeted the following muscle groups: lumbar paravertebral, hip flexors, hip adductors, hamstrings, and ankle flexors. Subjects were instructed to stretch to the point of feeling a slight discomfort, hold it for 30 seconds and to repeat each exercise three times.

The resistive exercises were dynamic and open chain, except for the squat. They targeted the following muscle groups: knee extensors, knee flexors, ankle flexors, and abdominals. Participants were instructed to perform three sets of 10 repetitions with an interval of one minute between each set. An individualized and moderate intensity regime using a 10-repetition maximum was prescribed according to the patient's tolerance and limitations. A two-meter elastic band (Thera-Band) was chosen as the resistive device because it is easy to carry and versatile. The only muscle group that did not use a load resistance were the abdominals because of the frequent compensations observed in our previous pilot study ${ }^{4}$.

All the prescription parameters remained unchanged across the study period, except for the intensity, which was assessed monthly at the adjusting sessions and progress was to move to the next color on the Thera-Band resistance scale. When color progression was not possible, the previous color was kept. In the cases where there was a difference in muscular performance between the lower limbs, the color of the weaker limb prevailed. If, during a specific exercise, the participant could not move the limb through the complete range of motion against gravity, an alternative posture (weightless) was prescribed.

The individuals were asked to execute the program at home twice a week with at least a one day interval between them. Due to the various levels of disabilities and the absence of supervision at home, the prescription of the posture and intensity of exercises were individualized, which permitted each participant to execute the exercises in a safe and effective way.

\section{Protocol}

The protocol consisted of a 20-week home-based exercise program. However, face-to-face sessions were required: three functional assessments, six training sessions, and six adjusting sessions (AS). The functional assessments occurred before the training sessions $\left(\mathrm{T}_{0}\right)$, and at eight $\left(\mathrm{T}_{1}\right)$ and 20 weeks $\left(\mathrm{T}_{2}\right)$ after the end of the training period. The same physiotherapist assessed all outcome measures.

After $\mathrm{T}_{0}$ and before the training period, the participant came to the Center for the first adjusting session $\left(\mathrm{AS}_{1}\right)$. At 
this point in time, the participants received all the instructions about the home-based exercises program and set the prescription parameters. Only after that was it possible to start the training period. The remaining adjusting sessions $\left(\mathrm{AS}_{2}-\mathrm{AS}_{6}\right)$ occurred monthly and aimed to progress the exercises.

The training sessions were planned to ensure correct performance of the exercises and to ensure proper exercise recording procedures. The training period was expected to last three weeks (two sessions per week). However, due to the difficulties reported by the TSP/HAM individuals in coming to the Center, this period could last up to six weeks.

At the last training session, the individual had to be able to demonstrate to the physical therapist a sufficient comprehension and adequate execution of the exercises. In the case where an individual had not learned the exercises, extra sessions could be offered, but the data of this individual would be excluded from the study. At that time, the participants received all the equipment and material required to perform the exercises (elastic bands, mat, data recording sheets and the exercise chart).

\section{Adherence, attendance, adverse events and barriers}

In order to monitor the adherence and the adverse events related to the home-based exercises program, the individuals had to complete exercise logs, recording the days they performed the exercises and the occurrence of any adverse events related to them, such as pain, fatigue, soreness, fasciculation or muscle cramp. In addition, the participants received weekly telephone contacts until the end of the eighth week post-training.

The adherence to the home sessions was considered "high", "moderate" and "low" for completing > 75\%; 50-75\% and $<50 \%$ of the required days ${ }^{16}$, respectively.

The attendance rate was defined as the presence at the face-to-face sessions. The reasons for the non-attendance were considered as barriers to the exercise practice.

\section{Outcome measures}

A clinical questionnaire was used to collect the characteristics data from individuals, such as socio-demographic information, TSP/HAM specific measures (disease duration, HTLV-I proviral load), number of falls in the last year, use of devices to walk and walking ability ${ }^{17}$. Disease-specific scales such as the Expanded Disability Status Scale ${ }^{18}$ and the Insituto de Pesquisa Clinica Evandro Chagas disability scale ${ }^{19}$ were also applied to evaluate severity in TSP/HAM. The latter is an instrument developed specifically to measure motor skills, spasticity, sensation and sphincter disabilities in TSP/HAM individuals.

The Timed Up and Go test (TUG) ${ }^{20}$ was used not as an outcome measure but to split the sample in two groups: $<20$ seconds $v s \geq 20$ seconds. This cutoff point has been used previously with older individuals ${ }^{20}$.
The outcome measures comprised the maximum voluntary isometric contraction of lower limbs (MVIC), Barthel Index and the 36-Item Short-Form Healthy Survey (SF-36).

The MVIC was measured by a load cell attached to an 8-channel electromyography amplifier (EMG_811 C - EMG System do Brasil Ltda). Data were analyzed by the SuiteMYO Program version 1.0.0.3 (PhD2 Consultoria e Sistemas Ltda, RJ, Brasil). Each MVIC was sustained for five seconds and repeated three times with an interval of approximately 20 seconds between each trial. The following muscle groups were monitored: hip flexors, knee extensors and knee flexors. All the measurements were done in the sitting position with the upper limbs crossed at the trunk level. The data average of the trials for each muscle group was calculated. The total score of hip flexors $\left(\mathrm{MVIC}_{\mathrm{HF}}\right)$, knee extensors $\left(\mathrm{MVIC}_{\mathrm{KE}}\right)$, and knee flexors $\left(\mathrm{MVIC}_{\mathrm{KF}}\right)$ resulted from the sum of data of both sides. The total score of both lower limbs $\left(\mathrm{MVIC}_{\mathrm{TLL}}\right)$ was the sum of all three total scores for the muscle groups.

The Barthel Index was applied to evaluate activity limitation. It is an instrument used to measure the performance of 10 basic daily living activities ${ }^{21}$.

The SF-36 assesses the quality of life and comprises 36 items representing eight general health concepts ${ }^{22}$. It was the only outcome measure that was applied at $\mathrm{T}_{0}$ and $\mathrm{T}_{2}$, while the others were applied at $\mathrm{T}_{0}, \mathrm{~T}_{1}$ and $\mathrm{T}_{2}$.

\section{Statistical analysis}

The statistical analysis was carried out using SPSS, version 16.0. The Kolmogorov-Smirnov test was used to analyze the normality of data, which identified that the majority of variables were non-parametric. Thus, all quantitative variables were expressed in median and range, and qualitative variables were expressed in absolute values and percentage.

The primary outcome measures were compared over time $\left(\mathrm{T}_{0} \times \mathrm{T}_{1} \times \mathrm{T}_{2}\right)$ with the Friedman test, except for the SF-36, for which the Wilcoxon test was used $\left(\mathrm{T}_{0} \times \mathrm{T}_{2}\right)$. The level of significance was $\mathrm{p}<0.05$ for all statistical tests.

\section{RESULTS}

Of the 164 individuals assessed, 34 (21\%) met the eligibility criteria (Figure 1). From those, only 23 participants (68\%) completed the study. The lack of transport and/or a caregiver/family member were the main reasons for refusals or loss.

Fifty-seven percent of the sample was female. Baseline characteristics of all analyzed individuals are shown in Table 1.

The median adherence rate to the home sessions was $90 \%$ (50-100\%). Seventy-eight percent of the participants had a high adherence rate to the home sessions and no one had low adherence.

The median attendance rate at the site-based sessions (functional assessments, training and adjusting sessions) was $68 \%(33-100 \%)$. Eighty-seven percent of the 


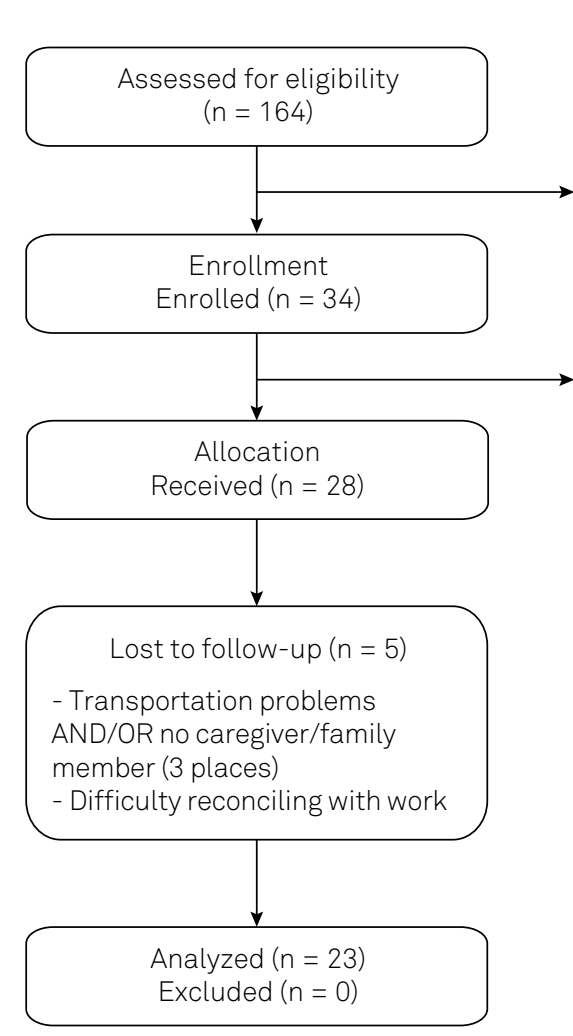

Excluded $(n=130)$

- Not meeting inclusion criteria $(n=122)$

- Transportation problems and/or no

caregiver/partner $(n=5)$

- Financial problems $(n=1)$

- Others $(n=2)$

Dropped out during training period $(n=6)$

- Transportation problems and/or no

caregiver/partner $(n=3)$

- Health problems $(n=2)$

- Difficult to reconcilie with work $(n=1)$

Figure 1. Flow of study participants.

Table 1. Baseline characteristics of participants $(n=23)$.

\begin{tabular}{|c|c|}
\hline Functional data & $\mathrm{n}(\%)$ \\
\hline Age $($ years)* & $53.1(28.3-71.6)$ \\
\hline \multicolumn{2}{|l|}{ TSP/HAM specific measures* } \\
\hline Proviral load ( $n^{\circ}$ copies/100 cells) & $5.4(1.4-39.7)$ \\
\hline Duration of disease (years) & $7.0(1.0-25.0)$ \\
\hline EDSS & $4.5(3.0 \vee 6.5)$ \\
\hline IPEC & $12(3-23)$ \\
\hline \multicolumn{2}{|l|}{ FACS } \\
\hline Restricted ambulation & $8(34.8)$ \\
\hline Independent ambulation & $15(65.2)$ \\
\hline \multicolumn{2}{|l|}{$N^{0}$ falls (last year) } \\
\hline None & $8(34.8)$ \\
\hline One fall & $5(21.7)$ \\
\hline$\geq 2$ falls & $10(43.5)$ \\
\hline \multicolumn{2}{|l|}{ Use of walking device } \\
\hline None & $13(56.5)$ \\
\hline Unilateral & $6(26.1)$ \\
\hline Bilateral & $4(17.4)$ \\
\hline \multicolumn{2}{|l|}{ Type of walking device } \\
\hline None & $13(56.5)$ \\
\hline Support of another person & $1(4.3)$ \\
\hline Crutches/Canes & $7(30.4)$ \\
\hline Walker & $1(4.3)$ \\
\hline Support of another person + Crutches/Canes & $1(4.3)$ \\
\hline
\end{tabular}

participants attended more than $50 \%$ of the site-based available sessions. Participants missed about $20 \%$ of the adjusting sessions. The most prevalent barrier for not attending the site-based sessions was concomitant health problems (35.4\%), such as fever, diarrhea, etc. Other causes were difficulties reconciling with work (15.3\%), difficulties with transportation (12.5\%), forgetfulness (11.5\%), lack of a caregiver/family member (8.3\%), and other (17\%).

The main adverse events possibly related to the exercise practice were fatigue and soreness $(78 \%)$, muscle cramps $(61 \%)$, and low back pain (11\%). These symptoms were transitory, of mild to moderate intensity, and not disabling.

There was a significant time effect of exercise practice in both groups. In the group $\mathrm{TUG}<20 \mathrm{~s}(\mathrm{n}=14)$, there was a significant increase of 2.8 kilogram force (kgf) in MVIC $_{\mathrm{HF}}$ between $\mathrm{T}_{0}$ and $\mathrm{T}_{2}(\mathrm{p}<0.01)$ and $1 \mathrm{kgf}$ between $\mathrm{T}_{1}$ and $\mathrm{T}_{2}(\mathrm{p}=0.02)$. For the $\mathrm{MVIC}_{\mathrm{TLL}}$, there was a significant increase of $3.2 \mathrm{kgf}$ between $\mathrm{T}_{0}$ and $\mathrm{T}_{2}(\mathrm{p}=0.03)$ and $1.4 \mathrm{kgf}$ between $\mathrm{T}_{1}$ and $\mathrm{T}_{2}(\mathrm{p}=0.03)$. These results are shown in Figure 2.

In relation to the SF-36 questionnaire, there was a significant improvement of $25 \%$ in the social functioning component in the TUG $<20 \mathrm{~s}$ group ( $\mathrm{p}=0.04)$. In contrast, the group TUG $\geq 20 \mathrm{~s}(\mathrm{n}=9)$ improved by $10 \%$ in the physical functioning component ( $p=0.01)$. All outcome measures across the time for both groups can be seen in Tables 2 and 3. 

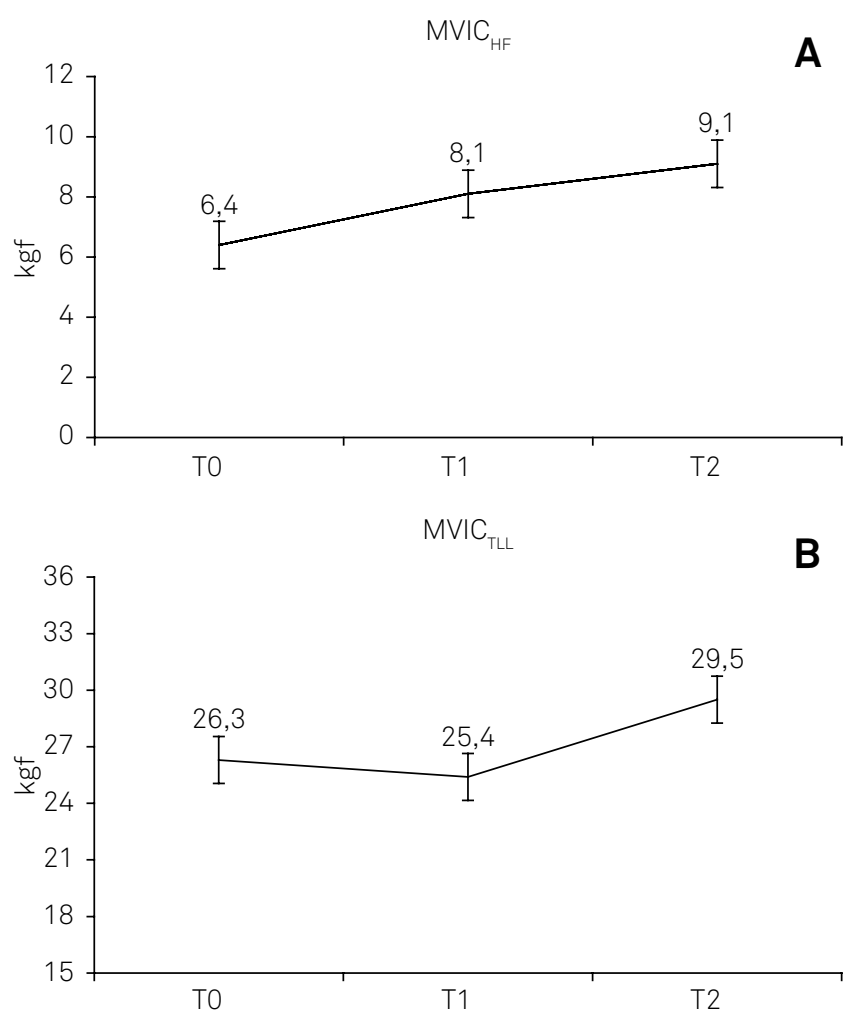

MVICHF: maximum voluntary isometric contraction of hip flexors; MVICTLL: maximum voluntary isometric contraction of total lower limbs score.

Figure 2. Effects of the home-based exercise program in MVIC in the TUG $<20$ s group. (a) Hip flexors and (b) total lower limbs score. There were significant $p$ values for the hip flexors between $\mathrm{T} 0$ and T2 ( $<<0.01)$ and T1 and T2 ( $=0.02)$ and for the total score of both lower limbs between T0 and T2 ( $=0.03)$ and T1 and T2 ( $<<0.03)$.

\section{DISCUSSION}

As far as we know, this is the first study that has investigated the feasibility and the effectiveness of a home-based exercise intervention in TSP/HAM individuals. It demonstrated that a home-based exercise program was feasible and safe and that participants had good adherence to the program. The adherence rate observed in this study (90\%) was comparable to other home-based programs, such as $72.2 \%$ in Huntington disease ${ }^{23}, 77 \%$ to $88 \%$ in stroke patients ${ }^{24}, 75.7 \%$ in older adults ${ }^{25}$ and $95 \%$ in multiple sclerosis patients ${ }^{12}$.

However, the attendance at the site-based sessions was moderate, which could have had an impact on the results. Health problems were the main reason for non-attendance, followed by difficulties reconciling with work, transportation, and lack of a caregiver/family member. It is possible that fewer sitebased sessions would increase attendance for the program.

The 20-week home-based exercise program improved muscle strength in TSP/HAM patients with milder disease, i.e., in individuals with $\mathrm{TUG}<20 \mathrm{~s}$. An increment in $\mathrm{MVIC}_{\mathrm{HF}}$ and $\mathrm{MVIC}_{\mathrm{TLL}}$ was observed in this group. The significant differences were seen between $T_{0}$ and $T_{2}$ and between $T_{1}$ and $\mathrm{T}_{2}$, which suggest that a longer supported period is necessary for positive results. An improvement in the muscular performance through a home-based exercise program in individuals with multiple sclerosis and amyotrophic lateral sclerosis has also been described ${ }^{12,16}$.

Table 2. Effects of the home-based exercise program in $T U G<20$ s group. Values are expressed in median (minimum-maximum).

\begin{tabular}{|c|c|c|c|c|}
\hline \multirow{2}{*}{ Variables } & \multicolumn{4}{|c|}{ TUG $<20 \mathrm{~s}$} \\
\hline & $\mathrm{T}_{0}$ & $\mathrm{~T}_{1}$ & $\mathrm{~T}_{2}$ & p \\
\hline \multicolumn{5}{|l|}{ Functions and structures } \\
\hline \multicolumn{5}{|l|}{ MVIC (kgf) } \\
\hline Hip flexors & $6.4(2.6-16.4)$ & $8.1(2.1-19.3)$ & $9.1(2.9-21.2)$ & $<0.01$ \\
\hline Knee extensors & $11.2(8.6-15.9)$ & $12.2(8.1-19.8)$ & $12.4(7.6-21.1)$ & 0.50 \\
\hline Knee flexors & $5.5(2.5-10.9)$ & $5.6(1.4-13.1)$ & $5.6(3-13.1)$ & 0.80 \\
\hline Lower limbs total score & $26.3(16.9-41.2)$ & $25.4(16.5-51.8)$ & $29.5(13.7-52)$ & 0.02 \\
\hline \multicolumn{5}{|l|}{ Activities } \\
\hline Barthel Index & $95(90-100)$ & $95(85-100)$ & $97.5(85-100)$ & 0.85 \\
\hline \multicolumn{5}{|l|}{ Quality of life } \\
\hline \multicolumn{5}{|l|}{ SF-36 } \\
\hline Physical functioning & $45(25-90)$ & - & $52.5(20-90)$ & 0.28 \\
\hline Role limitations due to physical problems & $37.5(0-100)$ & - & $50(0-100)$ & 0.22 \\
\hline Bodily pain & $51(22-100)$ & - & $46(0-100)$ & 0.89 \\
\hline General health perceptions & $39.5(27-97)$ & - & $52.5(20-82)$ & 0.16 \\
\hline Vitality & $45(10-100)$ & - & $55(25-85)$ & 0.11 \\
\hline Social functioning & $50(0-100)$ & - & $75(38-100)$ & 0.04 \\
\hline Role limitations due to emotional problems & $0(0-100)$ & - & $33.3(0-100)$ & 0.35 \\
\hline General mental health & $62(4-88)$ & - & $60(28-92)$ & 1 \\
\hline
\end{tabular}

TUG: timed up and go; $T_{0}$ : baseline assessment; $T_{1}: 8$ weeks after the end of training period assessment; $T_{2}: 20$ weeks after the end of training period assessment; MVIC: maximum voluntary isometric contraction; kgf: kilogram force. 
Table 3. Effects of the home-based exercise program in $T U G \geq 20$ s group. Values are expressed in median (minimum-maximum).

\begin{tabular}{|c|c|c|c|c|}
\hline \multirow{2}{*}{ Variables } & \multicolumn{4}{|c|}{ TUG $\geq 20 \mathrm{~s}$} \\
\hline & $\mathrm{T}_{0}$ & $\mathrm{~T}_{1}$ & $\mathrm{~T}_{2}$ & $\mathrm{p}$ \\
\hline \multicolumn{5}{|l|}{ Functions and structures } \\
\hline \multicolumn{5}{|l|}{ MVIC (kgf) } \\
\hline Hip flexors & $3.8(1.5-6.5)$ & $5.2(2-11.9)$ & $5.3(1.7-8.4)$ & 0.85 \\
\hline Knee extensors & $9.7(3.2-13.6)$ & $13.3(6.3-20.3)$ & $10.2(4.4-14.3)$ & 0.22 \\
\hline Knee flexors & $2.2(0.6-6.7)$ & $4.3(2.1-5.8)$ & $3.7(0.5-6)$ & 0.61 \\
\hline Lower limbs total score & $16(5.3-26.3)$ & $25.7(11.6-30.3)$ & $19.6(10.6-25.4)$ & 0.12 \\
\hline \multicolumn{5}{|l|}{ Activities } \\
\hline Barthel Index & $95(55-100)$ & $92.5(75-100)$ & $95(65-100)$ & 0.14 \\
\hline \multicolumn{5}{|l|}{ Quality of life } \\
\hline \multicolumn{5}{|l|}{ SF-36 } \\
\hline Physical functioning & $30(5-60)$ & - & $40(10-70)$ & 0.01 \\
\hline Role limitations due to physical problems & $0(0-100)$ & - & $0(0-75)$ & 0.34 \\
\hline Bodily pain & $31(12-84)$ & - & $41(22-62)$ & 0.8 \\
\hline General health perceptions & $52(45-97)$ & - & $52(37-87)$ & 0.55 \\
\hline Vitality & $65(20-100)$ & - & $60(50-85)$ & 0.31 \\
\hline Social functioning & $50(25-100)$ & - & $50(25-100)$ & 0.62 \\
\hline Role limitations due to emotional problems & $33(0-100)$ & - & $33.3(0-100)$ & 0.89 \\
\hline General mental health & $64(48-100)$ & - & $56(44-100)$ & 0.72 \\
\hline
\end{tabular}

TUG: timed up and go; $T_{0}:$ baseline assessment; $T_{1}: 8$ weeks after the end of training period assessment; $T_{2}: 20$ weeks after the end of training period assessment; $\mathrm{MVIC}$ : maximum voluntary isometric contraction; kgf: kilogram force.

Despite the favorable results of increased muscular strength in TUG $<20$ s group, no improvement was observed in the Barthel Index. Firstly, this could be related to the non-specificity of the exercises compared to the activities evaluated with the functional scale. Perhaps the prescription of functional exercises would result in better functional outcomes. Secondly, the ceiling effects of the Barthel Index could have obscured changes, since the patients were mostly independent.

An improvement in quality of life was also observed in TSP/HAM individuals in the TUG < 20 s group; however, this was seen only in the social functioning component. This component assesses the impact of physical health or emotional problems on social activities ${ }^{22}$. Martins et al. identified that the practice of physical activity was associated with a better quality of life in TSP/HAM individuals. Besides, it is also possible that the participation in exercise could have attenuated the level of depression, which is prevalent in about $30 \%$ of people living with HTLV-1, negatively affecting the quality of life ${ }^{26}$. The influence of exercise in humor diseases, such as depression, has been demonstrated previously in others populations ${ }^{27}$.

In TUG $\geq 20$ s group, a significant improvement in quality of life was also observed, but only in the physical functioning component of the SF-36. This domain assesses the presence and extent of physical limitations and has been used in many studies as a global measure of functioning. In general, the influence of home-based exercise programs on quality of life has been demonstrated in many neurological conditions, as in amyotrophic lateral sclerosis ${ }^{16}$, spinal cord injury $^{28}$ and multiple sclerosis ${ }^{29}$. We cannot maintain that the improvement in physical functioning in this group was due to a disease-modifying effect of exercise or due to its reversion of immobility effects secondary to the disease. It is possible that, similar to other neurological conditions, the exercises could have modified the sedentary lifestyle adopted by the majority of patients ${ }^{30}$.

It is unlikely that the results described in this study were due to the placebo effect. However, randomized controlled trials are required to confirm that hypothesis.

Despite the initial number of screened participants ( $n=164)$, the reduced sample size that completed the study limit the extrapolation of our results. Moreover, since the rate of patients with a recent diagnosis in our institution is very low, it is possible that the inclusion criteria related to the practice of exercise could have represented a selection bias and negatively influenced our sample. In other words, many participants had been diagnosed with TSP/HAM for more than one year and, that if they still had not practiced any kind of exercise until the enrollment in the study, they probably would have difficulties in participation in exercise programs.

In conclusion, the home-based exercises program was feasible and effective in improving impairments and quality of life in individuals with TSP/HAM. Further randomized controlled trials with exercise intervention are necessary in this population.

The good adherence to the home-based exercise program reinforces that strategies to facilitate access to rehabilitation services and promote health should be encouraged and implemented. A more detailed investigation of the barriers related to the practice of exercises in TSP/HAM people is also required. 
1. Gessain A, Barin F, Vernant JC, Gout O, Maurs L, Calender A et al. Antibodies to human T-lymphotropic virus type-l in patients with tropical spastic paraparesis. Lancet. 1985;2(8452):407-10. https://doi.org/10.1016/S0140-6736(85)92734-5

2. Osame M, Usuku K, Izumo S, Ijichi N, Amitani H, Igata A et al. HTLV-I associated myelopathy, a new clinical entity. Lancet. 1986;1 (8488):1031-2. https://doi.org/10.1016/S0140-6736(86)91298-5

3. Franzoi AC, Araújo AQ. Disability profile of patients with HTLV-I-associated myelopathy/tropical spastic paraparesis using the Functional Independence Measure (FIM). Spinal Cord. 2005;43(4):236-40. https://doi.org/10.1038/sj.sc.3101677

4. Facchinetti LD, Araújo AQ, Chequer GL, Azevedo MF, Oliveira RV, Lima MA. Falls in patients with HTLV-I-associated myelopathy/tropical spastic paraparesis (HAM/TSP). Spinal Cord. 2013;51(3):222-5. https://doi.org/10.1038/sc.2012.134

5. Shublaq M, Orsini M, Puccioni-Sohler M. Implications of HAM/TSP functional incapacity in the quality of life. Arq Neuropsquiatr. 2011;69(2A):208-11. https://doi.org/10.1590/S0004-282X2011000200013

6. Martins JV, Baptista AF, Araújo AQ.. Quality of life in patients with HTLV-1 associated myelopathy /tropical spastic paraparesis. Arq Neuropsquiatr. 2011;70(4):257-61. https://doi.org/10.1590/S0004-282X2012005000006

7. Castro-Costa CM, Araújo AQ, Menna-Barreto M, Penalva-de-Oliveira AC. [Guide of clinical management of HTLV patient: neurological aspects]. Arq Neuropsiquiatr. 2005;63(2B):548-51. Portuguese. https://doi.org/10.1590/S0004-282X2005000300036

8. Franzoi AC, Araújo AQ. Disability and determinants of gait performance in tropical spastic paraparesis/HTLV-I associated myelopathy (HAM/TSP). Spinal Cord. 2007;45(1):64-8. https://doi.org/10.1038/sj.sc.3101919

9. Martin F, Fedina A, Youshya S, Taylor GP. A 15-year prospective longitudinal study of disease progression in patients with HTLV-1 associated myelopathy in the UK.J Neurol Neurosurg Psychiatry. 2010;81(12):1336-40. https://doi.org/10.1136/jnnp.2009.191239

10. Rimmer JH, Rubin SS and Braddock D. Barriers to exercise in African American women with physical disabilities. Arch Phys Med Rehabil. 2000;81(2):182-8. https://doi.org/10.1016/S0003-9993(00)90138-2

11. Scelza WM, Kalpakjian CZ, Zemper ED, Tate DG. Perceived barriers to exercise in people with spinal cord injury. Am J Phys Med Rehabil. 2005;84(8):576-83. https://doi.org/10.1097/01.phm.0000171172.96290.67

12. DeBolt LS, McCubbin JA. The effects of home-based resistance exercise on balance, power, and mobility in adults with multiple sclerosis. Arch Phys Med Rehabil. 2004;85(2):290-7. https://doi.org/10.1016/j.apmr.2003.06.003

13. Dolbow DR, Gorgey AS, Ketchum JM, Moore JR, Hackett LA, Gater DR. Exercise adherence during home-based functional electrical stimulation cycling by individuals with spinal cord injury. Am J Phys Med Rehabil. 2012;91(11):922-30. https://doi.org/10.1097/PHM.0b013e318269d89f

14. De Castro-Costa CM, Araújo AQ, Barreto MM, Takayanagui OM, Sohler MP, Silva EL et al. Proposal for diagnostic criteria of tropical spastic paraparesis/HTLV-I-associated myelopathy (TSP/HAM). AIDS Res Hum Retroviruses. 2006;22(10):931-5. https://doi.org/10.1089/aid.2006.22.931

15. Bezner J. Prevention and promotion of health, wellness and fitness. In: Brody LT, editor. Therapeutic exercise: moving toward function. 3rd ed. Baltimore: Lippincott Williams \& Wilkins; 2011.
16. Bello-Haas VD, Florence JM, Kloos AD, Scheirbecker J, Lopate G, Hayes SM et al. A randomized controlled trial of resistance exercise in individuals with ALS. Neurology. 2007;68(23):2003-7. https://doi.org/10.1212/01.wnl.0000264418.92308.a4

17. Viosca E, Martínez JL, Almagro PL, Gracia A, González C. Proposal and validation of a new functional ambulation classification scale for clinical use. Arch Phys Med Rehabil. 2005;86(6):1234-8. https://doi.org/10.1016/j.apmr.2004.11.016

18. Kurtzke JF. Rating neurologic impairment in multiple sclerosis: an expanded disability status scale (EDSS). Neurology. 1983;33(11):1444-52. https://doi.org/10.1212/WNL.33.11.1444

19. Lima MA, Bica RB, Araújo AQ. Gender influence on the progression of HTLV-I associated myelopathy/tropical spastic paraparesis. J Neurol Neurosurg Psychiatry. 2005;76(2):294-6. https://doi.org/10.1136/jnnp.2004.035709

20. Podsiadlo D, Richardson S. The timed "Up \& Go": a test of basic functional mobility for frail elderly persons. J Am Geriatr Soc. 1991;39(2):142-8. https://doi.org/10.1111/j.1532-5415.1991.tb01616.x

21. Mahoney FI and Barthel DW. Functional evaluation: the barthel index. Md State Med J. 1965;14:61-5.

22. Ware JE Jr, Sherbourne CD. The MOS 36-item short-form health survey (SF-36). I. Conceptual framework and item selection. Med Care. 1992;30(6):473-83. https://doi.org/10.1097/00005650-199206000-00002

23. Khalil H, Quinn L, Deursen R, Dawes H, Playle R, Rosser A et al. What effect does a structured home-based exercise programme have on people with Huntington's disease? A randomized, controlled pilot study. Clin Rehabil. 2013;27(7):646-58. https://doi.org/10.1177/0269215512473762

24. Jurkiewicz MT, Marzolini S, Oh P. Adherence to a home-based exercise program for individuals after stroke. Top Stroke Rehabil. 2011;18(3):277-84. https://doi.org/10.1310/tsr1803-277

25. McAuley E, Wöjcicki TR, Gothe NP, Mailey EL, Szabo AN, Fanning $J$ et al. Effects of a DVD-delivered exercise intervention on physical function in older adults. J Gerontol A Biol Sci Med Sci. 2013;68(9):1076-82. https://doi.org/10.1093/gerona/glt014

26. Galvão-Castro AV, Boa-Sorte N, Kruschewsky RA, Grassi MF, Galvão-Castro B. Impact of depression on quality of life in people living with human T cell lymphotropic virus type 1 (HTLV-1) in Salvador, Brazil. Qual Life Res. 2012;21(9):1545-50. https://doi.org/10.1007/s11136-011-0066-6

27. Bridle C, Spanjers K, Patel S, Atherton NM, Lamb SE. Effect of exercise on depression severity in older people: systematic review and meta-analysis of randomised controlled trials. Br J Psychiatry. 2012;201 (3):180-5. https://doi.org/10.1192/bjp.bp.111.095174

28. Mulroy SJ, Thompson L, Kemp B, Hatchett PP, Newsam CJ, Lupold DG et al. Strengthening and optimal movements for painful shoulders (STOMPS) in chronic spinal cord injury: a randomized controlled trial. Phys Ther. 2011;91(3):305-24. https://doi.org/10.2522/ptj.20100182

29. Carter AM, Daley AJ, Kesterton SW, Woodroofe NM, Saxton JM, Sharrack B. Pragmatic exercise intervention in people with mild to moderate multiple sclerosis: a randomised controlled feasibility study. Contemp Clin Trials. 2013;35(2):40-7. https://doi.org/10.1016/j.cct.2013.04.003

30. Dalgas $\mathrm{U}$, Stenager E. Exercise and disease progression in multiple sclerosis: can exercise slow down the progression of multiple sclerosis? Ther Adv Neurol Disord. 2012;5(2):81-95. https://doi.org/10.1177/1756285611430719 